\title{
Interferência da dieta de alto grão sobre as características da carcaça e carne de cordeiros Texel
}

\section{Interference from high-grain diet on carcass and meat characteristics of Texel lambs}

\author{
Lisiane Dorneles de Lima ${ }^{1 *}$; Fabíola Cristine de Almeida Rêgo ${ }^{2}$; Celso Koetz Junior ${ }^{3}$; \\ Edson Luis de Azambuja Ribeiro ${ }^{4}$; Camila Constantino5; Laís Belan 6 \\ Marta Juliane Gasparine ${ }^{7}$; Ana Flavia Sanchez ${ }^{7}$; Marilice Zundt ${ }^{8}$
}

\begin{abstract}
Resumo
Este estudo teve como objetivo estudar o efeito de dietas com diferentes proporções de concentrado na terminação de cordeiros Texel sobre as características das carcaças e carne ovina. Foram utilizados 12 cordeiros da raça Texel com peso inicial de $20,1 \pm 2,34 \mathrm{~kg}$. Foram avaliadas rações com três proporções de concentrado na ração total $(60,80$ e $100 \%)$ e quatro repetições por tratamento. O concentrado foi composto por $15 \%$ suplemento nutricional $+85 \%$ grão de milho inteiro e o volumoso foi feno de Aveia (Avena strigosa). O rendimento verdadeiro da carcaça foi superior para os animais consumindo 100\% de concentrado na dieta, em média 58,3\%. Os valores da área de olho de lombo, acabamento e os pesos de costilhar e pernil foram superiores $(\mathrm{P}<0,05)$ para os animais recebendo 80 e $100 \%$ de concentrado na dieta em relação aos animais consumindo $60 \%$. Cordeiros recebendo $100 \%$ da dieta com alto grão apresentaram maiores rendimentos, área de olho de lombo e acabamento de carcaça, características essas relevantes em relação à questão produtiva fornecendo animais com maior porção de carne comestível e com qualidade satisfatória ao mercado consumidor. Os teores de concentrado na dieta não alteraram os parâmetros qualitativos e sensoriais da carne de cordeiros terminados em confinamento, características essas que poderão garantir maior aceitação do produto final, recomendando-se assim a utilização de dietas contendo alto teor de concentrado para cordeiros da raça Texel.
\end{abstract}

Palavras-chave: Coloração, força de cisalhamento, ovinos, pH, sensorial

\footnotetext{
Abstract

This study aimed to investigate the effect of diets with different proportions of concentrate in finishing lambs Texel on carcass characteristics and meat sheep. Twelve Texel lambs with an initial weight of $20.1 \pm 2.34 \mathrm{~kg}$ were used. The treatments consisted of three levels of concentrate in the total ration $(60$,

${ }^{1}$ Pesquisadora Dra da Embrapa Caprinos e Ovinos, Sobral, CE. E-mail: lisiane.lima@embrapa.br

${ }^{2}$ Prof $^{\mathrm{a}} \mathrm{Dr}^{\mathrm{a}}$ do Programa de Mestrado em Saúde e Produção de Ruminantes da Universidade Norte do Paraná, UNOPAR, Arapongas, PR. E-mail: fabíola_rego@yahoo.com.br

${ }^{3}$ Prof. Dr. da UNOPĀR, Arapongas, PR. E-mail: celsokoetzjr@yahoo.com.br

${ }^{4}$ Prof. Dr. do Dept ${ }^{\circ}$ de Zootecnia da Universidade Estadual de Londrina, UEL, Londrina, PR. Pesquisador do CNPq. E-mail: elar@uel.br

${ }^{5}$ Discente de Doutorado do Programa de Pós-graduação em Ciência Animal, UEL, Londrina, PR. E-mail: caconstantino@hotmail.com

${ }^{6}$ Discente de Mestrado do Programa de Mestrado em Saúde e Produção de Ruminantes, UNOPAR, Arapongas, PR. E-mail: lais_belan@hotmail.com

${ }^{7}$ Discentes de Graduação do curso de Medicina Veterinária, UNOPAR, Arapongas, PR. E-mail: martajuliane@hotmail.com; anaflaviasanchez@hotmail.com

${ }^{8}$ Prof $^{\mathrm{a}} \mathrm{Dr}^{\mathrm{a}}$ da Universidade do Oeste Paulista, UNOESTE, Presidente Prudente, SP. E-mail: mari@unoeste.com.br

* Autor para correspondência
} 
80 and $100 \%$ ) and four replicates per treatment.As the values of loin eye area, finish and weight of rib and ham were higher $(\mathrm{P}<0.05)$ for animals receiving 80 and $100 \%$ concentrate diet compared to animals consuming $60 \%$. Lambs receiving $100 \%$ of the diet with high grain had higher incomes, loin eye area and carcass finish, these characteristics relevant to the issue by providing animals most productive portion of edible meat and satisfactory quality to the consumer market. The levels of concentrate in the diet did not alter the qualitative parameters and sensory from lamb feedlot these characteristics that may ensure greater acceptance of the final product, so it is recommended the use of diets containing high concentrate to sheep.

Key words: Color, $\mathrm{pH}$, sheep, shearing force, sensory

\section{Introdução}

A demanda por proteína de origem animal para alimentação humana tem aumentado nas últimas décadas. Assim, a busca por alimentos mais saudáveis e a maior exigência em relação à qualidade dos produtos direcionaram parte do nicho de mercado a consumir carnes de melhor qualidade nutricional e sensorial (COSTA et al., 2008). Entre as carnes vermelhas, a carne ovina é uma excelente alternativa para atender a exigência desse mercado, a qual merece destaque pelo seu alto valor nutritivo, alta digestibilidade, elevados níveis de proteína, vitaminas do complexo $\mathrm{B}$, ferro, cálcio e potássio, além de ser rica em HDL ("colesterol bom”) e possuir baixos índices de gordura saturada, tornando-se uma opção para quem procura manter uma alimentação saudável e equilibrada (SILVA; CADAVEZ; AZEVEDO, 2007).

Em função disso, o consumo de carne ovina tem aumentado nos últimos anos, embora ainda seja menor quando comparado com o consumo de produtos de outras espécies. Assim, o mercado é promissor, pois há possibilidade de expandir o consumo interno da carne ovina e o país tem os atributos necessários para ser também um grande exportador (ALMEIDA JUNIOR et al., 2004). Entretanto, a cadeia produtiva de ovinos enfrenta dificuldades, com a oferta sazonal, dispersa e fragmentada, com predominância de pequenos lotes sem homogeneidade em tamanho, peso e terminação, colocando no mercado carcaças de animais com idade avançada e com características organolépticas indesejáveis (PÉREZ; CARVALHO,
2003). Porém, este cenário está mudando à medida que a carne ovina recebe destaque no mercado de carnes, assim vem ocorrendo mudanças na forma de apresentação e qualidade do produto ao consumidor.

Com essa perspectiva, surge então o interesse de intensificar a terminação de cordeiros, objetivando a rapidez da comercialização, antecipação da idade ao abate, promovendo a produção de carcaças com boa qualidade que atendam as exigências dos consumidores. De acordo com Costa et al. (2008), o genótipo, o peso ao abate, o sexo, o sistema de produção e principalmente a dieta devem ser considerados no planejamento produtivo, priorizando-se a qualidade nutricional e sensorial da carne, como forma de atender às novas perspectivas do mercado, sem deixar de se estabelecer adequada relação custo/benefício.

Assim, destaca-se que a relação volumoso:concentrado e o tipo de volumoso das dietas podem influenciar a qualidade da carne ovina. A alimentação mais volumosa pode gerar carnes mais escuras, em função do aumento da mioglobina do músculo (PRIOLO et al., 2002), e um maior acúmulo de carotenoídes na gordura pode torná-la mais amarelada (PRACHE; PRIOLO; GROLIER, 2003). Cordeiros terminados com maior quantidade de concentrado nas dietas podem apresentar carne mais macia (CIRIA; ASENJO, 2000), uma vez que a alimentação rica em concentrados resulta em carne com maior teor de gordura intramuscular (LEÃO et al., 2011).

Neste contexto, tem sido cada vez mais utilizado a prática da terminação de cordeiros em 
confinamentos recebendo dietas alto grão, sendo o grão de milho o principal ingrediente das dietas concentradas por ser uma fonte rica em amido.

Assim, pesquisas que avaliem os atributos qualitativos da carne são de suma importância para gerar informações aos consumidores sobre a cor e capacidade de retenção de água, uma vez que são fatores determinantes para a compra. Em face disso, objetivou-se estudar o efeito de dietas com diferentes proporções de concentrado na terminação de cordeiros Texel sobre as características das carcaças e carne ovina.

\section{Material e Métodos}

O experimento foi desenvolvido nas instalações do Hospital Veterinário da Universidade Norte do Paraná (UNOPAR), no campus de Arapongas, Paraná. $\mathrm{O}$ delineamento experimental foi inteiramente casualizado, com três tratamentos e quatro repetições por tratamento. Foram utilizados 12 cordeiros machos, da raça Texel, com aproximadamente 60

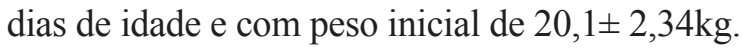

As instalações eram compostas por 12 baias individuais, com $6 \mathrm{~m}^{2}$ cada, cimentadas, com uma parte coberta e outra com solário e dotadas de cochos e bebedouros individuais. Os tratamentos foram constituídos de três proporções de concentrado na ração total $(60,80$ e 100\%). O concentrado foi composto por $15 \%$ de suplemento nutricional + $85 \%$ grão de milho inteiro e o volumoso por feno de aveia (Avena strigosa) (Tabela 1). O período experimental foi de 81 dias, sendo 15 dias de adaptação dos animais nas instalações e ao ajuste do consumo alimentar. $\mathrm{O}$ consumo da ração foi registrado diariamente, sendo realizada a pesagem da quantidade de alimentos fornecidos e das sobras de alimentos do dia anterior. A oferta de alimentos foi regulada semanalmente em $4 \%$ de matéria seca do peso vivo. Foram oferecidas duas refeições diárias ( 8 e 17 horas) e os animais tiveram acesso irrestrito à água.

Tabela 1. Composição alimentar e químico-bromatológica das rações experimentais com três proporções de concentrado.

\begin{tabular}{lccc}
\hline Composição, \% & Concentrado & Volumoso \\
\hline Matéria seca & 93,3 & 95,5 \\
Extrato etéreo & 2,64 & 1,79 \\
Proténa bruta & 19,0 & 5,99 \\
Fibra em detergente neutro & 33,4 & 84,3 \\
Fibra em detergente ácido & 18,3 & 49,8 \\
Matéria mineral & 13,4 & 6,31 & \\
& \multicolumn{3}{|c}{ Proporções de Concentrado, $\%$} \\
\cline { 2 - 3 } Matéria seca & $\mathbf{6 0}$ & $\mathbf{8 0}$ & $\mathbf{1 0 0}$ \\
Extrato etéreo & 94,6 & 93,7 & 2,64 \\
Proteína bruta & 2,13 & 2,47 & 19,0 \\
Fibra em detergente neutro & 11,21 & 16,4 & 33,4 \\
Fibra em detergente ácido & 63,9 & 43,6 & 18,3 \\
Matéria mineral & 37,2 & 24,6 & 13,4 \\
\hline
\end{tabular}

Fonte: Elaboração dos autores.

Antes do abate os animais passaram por um jejum sólido de 16 horas, e então foram transportados ao frigorífico por $40 \mathrm{~km}$ e permaneceram em baia de espera por 12 horas. Foi coletado o trato 
gastrointestinal, pesado cheio e vazio, para o cálculo do peso corporal vazio e foram separadas gorduras renal, mesentérica e omento (CEZAR; SOUSA, 2007). As carcaças foram pesadas logo após o abate (peso da carcaça quente) e após 24 horas de resfriamento (peso da carcaça resfriada). Os rendimentos de carcaça foram calculados pelas porcentagens dos pesos da carcaça quente e fria em relação ao peso vivo. Também foi realizado o rendimento verdadeiro, que é o peso da carcaça fria em relação ao peso corporal vazio (OSÓRIO; OSÓRIO, 2005). Foi realizada avaliação de acabamento, conformação e gordura estriada do flanco utilizando padrões fotográficos (CAÑEQUE; SAÑUDO, 2000). Posteriormente foram realizadas medidas de comprimento de carcaça e profundidade torácica, comprimento, perímetro e profundidade de perna de braço (OSÓRIO; OSÓRIO, 2005).

As meias carcaças esquerdas foram seccionadas na altura da última costela para avaliação da área de olho de lombo, espessura de gordura, profundidade, largura e marmoreio do músculo Longissimus dorsi (CEZAR; SOUZA, 2007). A taxa de marmoreio foi avaliada subjetivamente utilizando padrões fotográficos (AMSA, 2001), onde foram atribuídas notas de 1 a $6(1=$ traços de marmoreio e $6=$ marmoreio abundante). Foi realizada a separação da carcaça em cortes comerciais como paleta, pernil, costilhar e pescoço, para avaliar o rendimento dos cortes nobres.

Foi retirado da carcaça e enviado ao laboratório o Longissimus dorsi da carcaça direita, este foi fatiado formando as seguintes amostras: 3 bifes $(3 \mathrm{~cm})$ para avaliar força de cisalhamento; 2 bifes $(3 \mathrm{~cm})$ para análise sensorial; 1 bife $(2 \mathrm{~cm})$ para avaliar cor, $\mathrm{pH}$ e perda de água por pressão. Neste último bife foram realizadas medidas de cor trinta minutos após o corte. A cor foi analisada através do aparelho colorímetro portátil Minolta ${ }^{\circledR}$ para avaliação dos componentes $\mathrm{L}^{*}$ (luminosidade), $\mathrm{a}^{*}$ (componente vermelho-verde) e $b^{*}$ (componente amarelo-azul) que foram expressos no sistema de cor CIELAB. Com esses valores, calculou-se oângulo de tonalidade $\left(\mathrm{h}^{*}\right)$ pela equação $\mathrm{h}^{*}=\tan -1$ (b*/a*), e o índice de saturação, ou croma, (c*) a partir da equação $c^{*}=(a * 2+b * 2) 0,5$.

Foi realizada na mesma porção a perda de água por pressão (PAP), avaliada pelo método de pressão em papel filtro (BARBUT, 1996); perda de água no processamento, pesando o bife antes e após o período de maturação; foi realizada medida de $\mathrm{pH}$ interno - utilizando um aparelho portátil com eletrodo de inserção. O restante das amostras após o período experimental foram congeladas a $-18^{\circ} \mathrm{C}$ para posteriores análises.

A análise sensorial para a detecção do sabor da carne foi realizada por um grupo de 10 provadores treinados utilizando uma escala de intensidade e caracterização (ABNT, 1993).

A força de cisalhamento foi objetivamente medida através da utilização do aparelho texturômetro texture Analyser TA. TX-2. Para a obtenção das amostras foi utilizado um amostrador de aço de forma cilíndrica. Foram utilizados dois bifes por animal, de cada bife foram retiradas três sub-amostras de aproximadamente $1,25 \mathrm{~cm}$ de espessura, e cada sub-amostra foi cisalhada uma única vez, dando um total de seis leituras por animal (WHIPPLE et al., 1990).

Os dados foram submetidos ao teste de normalidade de Shapiro-Wilk, de Wilcoxone, quando verificada normalidade dos dados ( $\mathrm{P}>$ $0,05)$, foi realizada a análise de variância. Dados que não apresentaram distribuição normal $(\mathrm{P}<0,05)$ foram transformados. Quando verificado efeito das proporções de concentrado na dieta sobre as variáveis estudadas à nível de 5\% de probabilidade, as médias foram comparadas pelo teste Tukey utilizando-se o programa (SAS, versão 9.2).

\section{Resultados e Discussão}

Os resultados referentes ao peso ao abate dos cordeiros não diferiram entre os tratamentos $(\mathrm{P}>0,05)$; Tabela 2). No entanto, os pesos destas 
variáveis foram numericamente superiores para os animais que receberam maiores níveis de suplementação (80 e 100\%), o que provavelmente refletiu na superioridade significativa para o peso de corporal vazio (PCV), de carcaça quente (PCQ) e fria (PCF) destes animais em relação ao grupo consumindo $60 \%$ de concentrado. Não houve efeito do teor de concentrado no rendimento de carcaça quente (RCQ) e fria (RQF) dos animais. Estes resultados estão dentro da faixa de variação para rendimento de carcaça ovina que é de 40 a $60 \%$, segundo Sañudo e Sierra (1986). Por outro lado, o rendimento verdadeiro (RV) da carcaça foi superior $(\mathrm{P}>0,05)$, para os animais consumindo $100 \%$ de concentrado na dieta, diferindo estatisticamente dos demais tratamentos, apresentando em média 58,3\%. Este resultado esta associado ao menor conteúdo gastrointestinal dos animais consumindo 100\% de grão (Tabela, 2). Os valores encontrados neste estudo são superiores aos encontrados por Martins et al. (1999), com 54,86\%, em cordeiros mestiços Texel abatidos aos 30 e $32 \mathrm{~kg}$ de peso vivo. Garcia et al. (2004), avaliando as características de carcaça de ovinos Santa Inês, recebendo rações com $80 \%$ de concentrado e 2,8 Mcal EM/kg de MS, encontraram valores de $17,33 \mathrm{~kg}, 49,66 \%$ e $47,56 \%$, para peso da carcaça fria, rendimento verdadeiro da carcaça e rendimento comercial da carcaça, respectivamente.

Tabela 2. Peso no abate, peso da carcaça quente, peso da carcaça fria, peso de corpo vazio, conteúdo gastrointestinal, rendimento de carcaça quente, rendimento de carcaça fria e rendimento verdadeiro e perda por resfriamento da carcaça de cordeiros recebendo rações com diferentes proporções de concentrado.

\begin{tabular}{|c|c|c|c|c|c|}
\hline & \multicolumn{3}{|c|}{ Proporções de Concentrado,\% } & \multirow[t]{2}{*}{ Probabilidade } & \multirow[t]{2}{*}{$\mathrm{CV} \%$} \\
\hline & 60 & 80 & 100 & & \\
\hline Peso de abate, $\mathrm{kg}$ & 36,6 & 43,6 & 41,7 & 0,2017 & 9,58 \\
\hline Peso carcaça quente, $\mathrm{kg}$ & $17,1^{\mathrm{b}}$ & $21,9^{\mathrm{a}}$ & $20,4^{\mathrm{a}}$ & 0,0264 & 7,81 \\
\hline Peso carcaça fria, $\mathrm{kg}$ & $16,5^{\mathrm{b}}$ & $21,3^{\mathrm{a}}$ & $19,8^{\mathrm{a}}$ & 0,0232 & 7,88 \\
\hline Peso de corpo vazio, $\mathrm{Kg}$ & $30,1^{\mathrm{b}}$ & $40,0^{\mathrm{a}}$ & $35,0^{\mathrm{a}}$ & 0,0216 & 8,31 \\
\hline Conteúdo gastrointestinal, $\mathrm{kg}$ & $6,27^{\mathrm{a}}$ & $5,29^{\mathrm{b}}$ & $5,52^{\mathrm{b}}$ & 0,0421 & 3,98 \\
\hline Rendimento de carcaça quente, $\%$ & 46,7 & 50,3 & 49,1 & 0,1909 & 4,23 \\
\hline Rendimento de carcaça fria, $\%$ & 45,0 & 48,9 & 47,6 & 0,1396 & 4,28 \\
\hline Rendimento verdadeiro, $\%$ & $56,9^{\mathrm{b}}$ & $55,2^{\mathrm{b}}$ & $58,3^{\mathrm{a}}$ & 0,0185 & 2,84 \\
\hline Perda por resfriamento, $\%$ & $3,69^{\mathrm{a}}$ & $2,66^{\mathrm{b}}$ & $3,11^{\mathrm{b}}$ & 0,0056 & 8,80 \\
\hline
\end{tabular}

Médias seguidas de letras diferentes diferem pelo teste de Tukey a $5 \%$ de probabilidade; $\mathrm{CV} \%=$ coeficiente de variação.

Fonte: Elaboração dos autores.

Portanto, é importante ressaltar os bons resultados de rendimento verdadeiro obtidos com dietas com alto grão, foram em média de 56,8\%, o que é relevante do ponto de vista econômico e produtivo, pois é através do rendimento de carcaça que uma menor ou maior porção de material comestível torna-se disponível para comercialização e consumo após o abate dos animais. Assim, o RV é que determina o maior ou menor custo da carne para o consumidor, motivo relevante para despertar o interesse para esse parâmetro, sendo um incentivo para os criadores que investem nesta atividade (PÉREZ et al., 2002).

Não houve diferença significativa $(\mathrm{P}>0,05)$ para perda no resfriamento (PR) entre os tratamentos 80 e 100\% de concentrado na dieta (Tabela 2). No entanto, estes menores $(\mathrm{P} \leq 0,05)$ do que o observado com a dieta com $60 \%$. Este resultado pode estar associado ao fato que os animais que receberam maiores quantidades de concentrado, apresentaram maiores deposições de gordura, as quais proporcionam menores perdas de água na 
carcaça, quando colocados em resfriamento, pois confere proteção à carcaça (SILVA SOBRINHO, 1999). Os valores de perdas por resfriamento observados, neste estudo, estão dentro dos níveis máximos considerados aceitáveis (3,0 -4,0\%), demonstrando que o peso ao abate e os diferentes tratamentos conferiram quantidade satisfatória de cobertura de gordura na carcaça.

Corroborando com este estudo, Alves et al. (2003), ao avaliarem as características de carcaça de ovinos Santa Inês alimentados com dietas contendo diferentes teores de energia, que continham 2,42; 2,66; e 2,83 Mcal de energia metabolizável (EM)/kg de matéria seca, observaram efeito linear crescente para PCQ, RCQ, PCF, RCF e PCV. Enquanto que para PR e RV não foram influenciados pelos teores de energia na dieta.
Não houve diferença $(\mathrm{P}>0,05)$ para os pesos absolutos de paleta e pescoço, assim como para os rendimentos dos cortes comerciais avaliados (Tabela 3). No entanto, os pesos de costilhar e pernil foram superiores $(\mathrm{P}<0,05)$ para os animais recebendo 80 e $100 \%$ de concentrado na dieta em relação aos animais consumindo 60\%. Estes resultados podem ser devido ao maior consumo de energia metabolizável pelos animais que estavam recebendo maiores teores de concentrado na dieta, uma vez que estes cortes apresentam maior quantidade de tecido muscular e adiposo, quando comparados aos demais. Kempster et al. (1987) descreveram que a deposição de gordura na carcaça ocorre de forma rápida pelo lombo e costilhar, o que pode estar associado à maior deposição de gordura nesta região nos animais alimentados com dietas mais energéticas.

Tabela 3. Pesos e porcentagens dos cortes comerciais da meia carcaça esquerda de cordeiros recebendo rações com diferentes proporções de concentrado.

\begin{tabular}{|c|c|c|c|c|c|}
\hline & \multicolumn{3}{|c|}{ Proporções de Concentrado,\% } & \multirow[t]{2}{*}{ Probabilidade } & \multirow[t]{2}{*}{$\mathrm{CV} \%$} \\
\hline & 60 & 80 & 100 & & \\
\hline \multicolumn{6}{|c|}{ Pescoço } \\
\hline $\mathrm{Kg}$ & 0,47 & 0,55 & 0,64 & 0,2339 & 22,9 \\
\hline$\%$ & 5,66 & 5,14 & 6,36 & 0,3258 & 18,2 \\
\hline \multicolumn{6}{|c|}{ Costilhar } \\
\hline $\mathrm{Kg}$ & $3,24^{b}$ & $4,62^{\mathrm{a}}$ & $4,08^{\mathrm{a}}$ & 0,0040 & 6,84 \\
\hline$\%$ & 39,3 & 43,3 & 41,5 & 0,3046 & 6,35 \\
\hline \multicolumn{6}{|c|}{ Pernil } \\
\hline $\mathrm{Kg}$ & $2,70^{\mathrm{b}}$ & $3,44^{\mathrm{a}}$ & $3,23^{\mathrm{a}}$ & 0,0337 & 7,56 \\
\hline$\%$ & 32,8 & 32,2 & 32,7 & 0,4222 & 2,14 \\
\hline \multicolumn{6}{|c|}{ Paleta } \\
\hline $\mathrm{Kg}$ & 1,65 & 2,03 & 1,86 & 0,1149 & 9,94 \\
\hline$\%$ & 20,0 & 19,0 & 18,8 & 0,1883 & 4,20 \\
\hline
\end{tabular}

Médias seguidas de letras diferentes diferem pelo teste de Tukey a $5 \%$ de probabilidade.

CV \%=coeficiente de variação.

Fonte: Elaboração dos autores.

Os rendimento dos cortes observados, neste estudo, estão próximos aos verificados por Frescura et al. (2005), que testaram diferentes sistemas alimentares na terminação de cordeiros Ile de France $\times$ Texel, obtendo valores médios de $33,3 \%$ para perna, $19,2 \%$ para paleta e $6,1 \%$ para pescoço.

As medidas de comprimento e largura da perna, comprimento e perímetro de braço e profundidade do tórax não foram influenciadas $(\mathrm{P}>0,05)$ pelos teores de concentrados (Tabela 4). No entanto, 
o comprimento interno da carcaça, perímetro de perna e a largura do braço, apresentaram diferença $(\mathrm{P}<0,05)$, sendo que os animais que consumiram $80 \%$ e $100 \%$ apresentaram médias superiores para essas medidas em relação ao tratamento com $60 \%$ de concentrado na dieta. Da mesma forma, Pinheiro et al. (2007) também encontraram efeito linear para o perímetro de perna, sendo que os animais que receberam mais concentrado $(70 \%)$ obtiveram maior valor.

Tabela 4. Medidas morfométricas das carcaças de cordeiros recebendo rações com diferentes proporções de concentrado.

\begin{tabular}{|c|c|c|c|c|c|}
\hline & \multicolumn{3}{|c|}{ Proporções de Concentrado,\% } & \multirow[t]{2}{*}{ Probabilidade } & \multirow[t]{2}{*}{$\mathrm{CV} \%$} \\
\hline & 60 & 80 & 100 & & \\
\hline Comprimento Perna $(\mathrm{cm})$ & 39,2 & 40,1 & 40,0 & 0,8271 & 7,06 \\
\hline Comprimento Interno carcaça $(\mathrm{cm})$ & $57,5^{\mathrm{b}}$ & $60,1^{\mathrm{a}}$ & $58,5^{\mathrm{ab}}$ & 0,0761 & 5,53 \\
\hline Profundidade Perna $(\mathrm{cm})$ & 11,3 & 12,0 & 12,0 & 0,3851 & 5,23 \\
\hline Perímetro Perna (cm) & $39,4^{\mathrm{b}}$ & $42,9^{\mathrm{a}}$ & $42,0^{\mathrm{a}}$ & 0,0426 & 2,97 \\
\hline Comprimento Braço (cm) & 18,5 & 22,1 & 18,8 & 0,3640 & 15,3 \\
\hline Profundidade Braço (cm) & $6,07^{\mathrm{b}}$ & $6,92^{\mathrm{a}}$ & $6,50^{\mathrm{ab}}$ & 0,0456 & 5,81 \\
\hline Perímetro Braço(cm) & 19,6 & 20,4 & 20,0 & 0,3644 & 5,11 \\
\hline Profundidade Tórax(cm) & 25,4 & 26,9 & 25,2 & 0,4870 & 5,77 \\
\hline
\end{tabular}

Médias seguidas de letras diferentes diferem pelo teste de Tukey a 5\% de probabilidade.

Fonte: Elaboração dos autores.

A área de olho-de-lombo (AOL) foi superior $(\mathrm{P}<0,05)$ para os animais que consumiram maiores proporções de concentrados (Tabela 5). Isso pode ser devido ao maior consumo de energia da dieta, o que favoreceu maiores quantidades de músculos, uma vez que AOL é uma medida que reflete a composição cárnea da carcaça. As médias de AOL observados, neste estudo, foram superiores aos $11,19 \mathrm{~cm}^{2}$ observados por Neres et al. (2001) ao trabalhar com cordeiros confinados.

Tabela 5. Medidas do lombo obtidas por diferentes métodos em cordeiros recebendo rações com diferentes proporções de concentrado.

\begin{tabular}{|c|c|c|c|c|c|}
\hline & \multicolumn{3}{|c|}{ Proporções de Concentrado,\% } & \multirow[t]{2}{*}{ Probabilidade } & \multirow[t]{2}{*}{$\mathrm{CV} \%$} \\
\hline & 60 & 80 & 100 & & \\
\hline Espessura de gordura (mm) & 1,51 & 1,76 & 2,23 & 0,7443 & 42,2 \\
\hline Profundidade músculo (mm) & 55,2 & 60,5 & 60,8 & 0,3258 & 7,85 \\
\hline Largura músculo (mm) & 30,8 & 35,1 & 36,9 & 0,1807 & 12,1 \\
\hline Área de olho de lombo $\left(\mathrm{cm}^{2}\right)$ & $13,6^{\mathrm{b}}$ & $16,6^{\mathrm{a}}$ & $17,6^{\mathrm{a}}$ & 0,0401 & 11,5 \\
\hline Gordura estriada do Flanco & 1,63 & 1,70 & 1,75 & 0,7480 & 38,3 \\
\hline Acabamento & $2,46^{\mathrm{b}}$ & $2,53^{\mathrm{ab}}$ & $3,25^{\mathrm{a}}$ & 0,0406 & 19,9 \\
\hline Marmoreio & 2,05 & 2,27 & 2,75 & 0,9929 & 33,5 \\
\hline
\end{tabular}

Médias seguidas de letras diferentes diferem pelo teste de Tukey a $5 \%$ de probabilidade;

Área de Olho de lombo, $\mathrm{y}=1050,3+12,08 \mathrm{x}, \mathrm{r}^{2}=0,44$; Acabamento $\mathrm{y}=0,46+0,02 \mathrm{X}, \mathrm{R}^{2}=0,49$.

Fonte: Elaboração dos autores. 
Não foram encontradas diferenças $(\mathrm{P}>0,05)$ entre os teores de concentrados para os valores de medidas de espessura de gordura, marmoreio e gordura no flanco (Tabela 5). Entretanto, os valores de acabamento apresentaram valores superiores $(\mathrm{P}<0,05)$ para os animais que receberam 100\% de concentrado, o que está relacionado com alta ingestão energética, contribuindo para o acúmulo de gordura acentuado por toda a carcaça. A cobertura de gordura é importante indicador de qualidade, porque, além de aparentemente influir na solubilidade do colágeno da carne, afeta diretamente a velocidade de resfriamento da carcaça, comportando-se como isolante térmico e interferindo no processo de conversão do músculo em carne (FELÍCIO, 1999).

Neste estudo, os valores de $\mathrm{pH}$ permaneceram relativamente constantes, considerados dentro da faixa de $\mathrm{pH}$ normal para a carne ovina, que se situa entre 5,5 a 5,8 (SILVA SOBRINHO et al., 2005). Foi observado que quando os animais consumiram rações com $100 \%$ de grão não houve efeito nos valores de $\mathrm{pH}$ da carne (Tabela 6). Não houve influência do teor de concentrado na coloração da carne $(\mathrm{P}>0,05)$, portanto, o fato da qualidade da dieta não influenciar o $\mathrm{pH}$ é um fator positivo, uma vez que o $\mathrm{pH}$ da carne modifica suas características de qualidade (cor, capacidade de retenção de água e maciez), além de alterar as características organolépticas. Estes resultados vem corroborar com estudo de Zeola et al. (2002) ao utilizarem níveis crescentes de concentrado na dieta (30, 45 e $60 \%$ ) para cordeiros em confinamento, em que não observaram influência para os valores de $\mathrm{pH}$ e coloração da carne.

Tabela 6. Valores de pH, coloração, capacidade de retenção de água, perda de peso por cocção e força de cisalhamento da carne de cordeiros recebendo rações com diferentes proporções de concentrados.

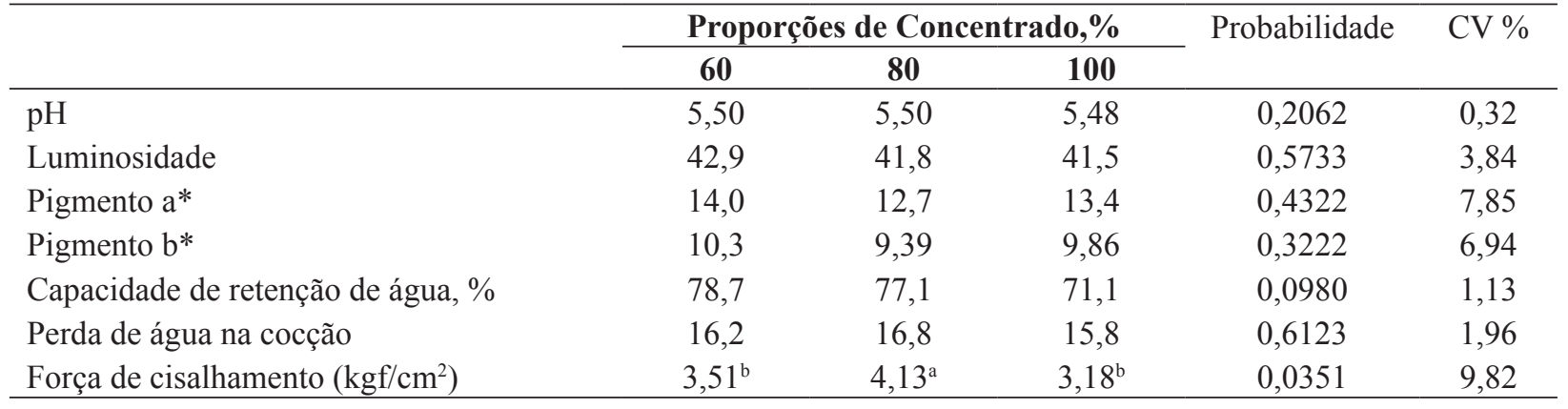

Médias seguidas de letras diferentes diferem pelo teste de Tukey a $5 \%$ de probabilidade. Luminosidade ( $\mathrm{L}^{*}$ ) / Intensidade de vermelho $\left(\mathrm{A}^{*}\right)$ e Intensidade de amarelo $\left(\mathrm{B}^{*}\right)$.

Fonte: Elaboração dos autores.

Fato de não ter alterado o $\mathrm{pH}$ da carne, provavelmente implicou na ausência do efeito $(\mathrm{P}>0,05)$ do teor de concentrado sobre a capacidade de retenção de água (CRA). Em relação aos valores da capacidade de retenção da água da carne observados, neste estudo, são adequados para manter a qualidade da carne, uma vez que, carnes com menor capacidade de retenção de água implicam perdas do valor nutritivo pelo exsudato liberado, resultando em carne mais seca e com menor maciez (ZEOLA et al., 2002).

Da mesma forma que a CRA, os valores encontrados para a perda de peso por cozimento (PPC) não diferiram $(\mathrm{P}>0,05)$. A perda de peso no cozimento é uma importante característica de qualidade, associada ao rendimento da carne no momento do consumo (PARDI et al., 1993), podendo 
ser influenciada pela capacidade de retenção de água nas estruturas da carne (BOUTON.; HARRIS; SHORTHOSE, 1971).

A força de cisalhamento (FC), foi superior $(\mathrm{P}<0,05)$ para os animais que receberam $80 \%$ de concentrado. Segudo Maturano (2003), a FC é um método de avaliação da maciez da carne e consiste em medir a força necessária para o corte de uma seção transversal de um determinado músculo, sendo que quanto maior a força utilizada, menor será a maciez. A média da FC obtida, deste estudo, foi igual às divulgadas por Babiker, El Khider e Shafie (1990), observaram no Longissimus dorsi de cordeiros resultados médios de FC $3,6 \mathrm{~kg} / \mathrm{cm}^{2}$. Portanto, nestas condições, todas as amostras das carnes analisadas, apresentaram-se muito macias, fato associado a qualidade da dieta e a idade dos animais (4 meses). Sañudo (2002) relatou que valores crescentes ou decrescentes para força de cisalhamento podem ser encontrados em animais jovens, de acordo com a idade de abate, talvez em função de interações entre diferentes taxas de deposição de colágeno e gordura no músculo do animal.

A dieta não interferiu $(\mathrm{P}>0,05)$ os parâmetros como odor, suculência, maciez e aceitação global das carnes dos cordeiros. Da mesma forma, Ferrão et al. (2009) verificaram que o uso de dietas com concentrado não promoveu diferenças significativas perceptíveis pelo painel sensorial nos parâmetros de sabor, maciez e suculência na carne de cordeiros Santa Inês.

Dentre os resultados obtidos, as carnes dos cordeiros de acordo com os provadores, a intensidade de odor, os animais apresentaram resultados semelhantes, os quais estão entre intenso, moderado e ligeiro. Para a suculência, as amostras apresentaram-se como pouca e moderada suculência, esta segue a mesma tendência da maciez. Apesar de não ter diferido $(\mathrm{P}>0,05)$ os animais que consumiram $100 \%$ de concentrado na dieta, apresentaram numericamente maior suculência, maciez e aceitação global, o que provavelmente esta associada ao maior conteúdo de gordura de marmoreio e menor força de cisalhamento encontrado na carne desses animais. Resultado importante, uma vez que essas características organolépticas associadas à maciez determinam a sensação agradável ou desagradável que provoca a aceitação ou a recusa pelo consumidor. De acordo com a aceitabilidade global, que define o valor 1 como extremamente inaceitável e 9 como extremamente aceitável, todas as carnes apresentaram resultados entre ligeiramente aceitável e moderadamente aceitável.

\section{Conclusão}

Cordeiros recebendo $100 \%$ da dieta com alto grão apresentaram maiores rendimentos, área de olho de lombo e acabamento de carcaça, características essas relevantes em relação à questão produtiva fornecendo animais com maior porção de carne comestível e com qualidade satisfatória ao mercado consumidor.

Os teores de concentrado na dieta não alteraram os parâmetros qualitativos e sensoriais da carne de cordeiros terminados em confinamento, características essas que poderão garantir maior aceitação do produto final, recomendando-se assim a utilização de dietas contendo alto teor de concentrado para cordeiros da raça Texel.

\section{Agradecimentos}

À empresa Premix pelo auxílio financeiro, a FUNADESP e a Universidade Norte do Paraná pelo apoio durante o desenvolvimento deste trabalho.

\section{Referências}

ALMEIDA JUNIORR, G. A.; COSTA, C.; MONTEIRO, A. L. G.; GARCIA, C. A. G.; MUNARI, D. P.; NERES, M. A. Qualidade da carne de cordeiros criados em creepfeeding com silagem de grãos úmidos de milho. Revista Brasileira de Zootecnia, Viçosa, v. 33, n. 4, p. 1039-1047, 2004. 
ALVES, K. S.; CARVALHO, F. F. R. de; FERREIRA, M. de A.; VÉRAS, A. S. C.; MEDEIROS, A. N. de; NASCIMENTO, J. F. do; NASCIMENTO, L. R. S.; ANJOS, A. V. A. dos. Níveis de energia em dietas para ovinos santa inês: características de carcaça e constituintes corporais. Revista Brasileira de Zootecnia, Viçosa, v. 32, n. 6, p. 1927-1936, 2003.

AMERICAN MEAT SCIENCE ASSOCIATION AMSA. Handbook meat evaluation. Champaign: AMSA, 2001.

ASSOCIAÇÃO BRASILEIRA DE NORMAS TÉCNICAS. NBR 12806: análise sensorial dos alimentos e bebidas: terminologia. São Paulo: ABNT, 1993.

BABIKER, S. A.; EL KHIDER, I. A.; SHAFIE, S. A. Chemical composition and quality attributes of goat meat and lamb. Meat Science, Barking, v. 28, n. 3, p. 273-277, 1990.

BARBUT, S. Estimates and detection of the PSE problem in young turkey breast meat. Canadian Journal Animal Science, Ottawa, v. 76, n. 3, p. 455-457, 1996.

BOUTON, P. E.; HARRIS, P. V.; SHORTHOSE, W. R. Effect of ultimate $\mathrm{pH}$ upon the water-holding capacity and tenderness of mutton. Journal of Food Science, Chicago, Illinois, v. 36, n. 3, p. 435-439, 1971.

CAÑEQUE, V.; SAÑUDO, C. Metodología para el estudio de la calidad de la canal y de la carne en rumiantes. INIA: Madrid, 2000.

CEZAR, M. F.; SOUSA, W. H. Carcaças ovinas e caprinas: obtenção - avaliação - classificação. Uberaba: Agropecuária Tropical, 2007.

CIRIA, J.; ASENJO, B. Factores a considerar enelpresacrificioypostsacrificio. In: CAÑEQUE, V.; SAÑUDO, C. Metodología para elestudio de lacalidad de la canal y de la carne enrumiantes. Madrid: Instituto Nacional de Investigación y Tecnología Agraria y Alimentaria, 2000. p. 19-45.

COSTA, R. G.; CARTAXO, F. Q.; SANTOS, N. M.; QUEIROGA, R. C. R. E. Carne caprina e ovina: composição lipídica e características sensoriais. Revista Brasileira de Saúde e Produção Animal, Salvador, v. 9, n. 3, p. 497-506, 2008.

FELÍCIO, P. E. Qualidade de carne bovina: características físicas e organolépticas. In: REUNIÃO ANUAL DA SOCIEDADE BRASILEIRA DE ZOOTECNIA, 36., 1999, Porto Alegre. Anais... Porto Alegre: Sociedade Brasileira de Zootecnia, 1999. p. 89-97.

FERRÃO, S. P. B.; BRESSAN, M. C.; OLIVEIRA, R.; PÉREZ, J. R. O.; RODRIGUES, É. C.; NOGUEIRA, D.

A. Características sensoriais da carne de cordeiros da raça Santa Inês submetidos a diferentes dietas. Ciência eAgrotecnologia, Lavras, v. 33, n. 1, p. 185-190, 2009.

FRESCURA, R. B. M.; PIRES, C. C.; SILVA, J. H. S.; MÜLLER, L.;CARDOSO, A.; KIPPERT, C. J.; PERESNETO, D.; SILVEIRA, C. D. da; ALEBRANTE, L.; THOMAS, L. Avaliação da proporção dos cortes dacarcaça, características da carne e avaliação dos componentes do peso vivo de cordeiros. Revista Brasileira de Zootecnia, Viçosa, v. 34, n. 4, p. 167-174, 2005.

GARCIA, I. F. F.; PEREZ, J. R. O.; BONAGURIO, S.; LIMA, A. L.; QUINTÃO, F. A. Estudo dos cortes da carcaça de cordeiros santa inês puros e cruzas Santa Inês comTexel, Ile de France e Bergamácia. RevistaBrasileira de Zootecnia, Viçosa, v. 33, n. 2, p. 453-462, 2004.

KEMPSTER, A. J.; CROSTON, D.; GUY, D. R.; JONES, D. W. Growth and carcass characteristics of crossbred lambs by ten sire breeds, compared at the same estimated carcass subcutaneous fat proportion. Animal Production, Bletchley, v. 44, n. 1, p. 83-98, 1987.

LEÃO, A. G.; SILVA SOBRINHO, A. G.; MORENO, G. M. B.; SOUZA, H. B. A.; PEREZ, H. L.; LOUREIRO, C. M. B. Características nutricionais da carne de cordeiros terminados com dietas contendo cana-de-açúcar ou silagem de milho e dois níveis de concentrado. Revista Brasileira de Zootecnia, Viçosa, v. 40, n. 5, p. 10721079, 2011.

MARTINS, E. N.; MACEDO, F. A. F.; MACEDO, R. M. G.; MAESTA, S. A. Desempenho e características quantitativas da carcaça de cordeiros mestiços texel, terminados em confinamento, com diferentes níveis de energia. REUNIÃO ANUAL DA SOCIEDADE BRASILEIRA DE ZOOTECNIA, Rio Grande do Sul, 1999. Anais... Rio Grande do Sul: SBZ, 1999. CD-ROM.

MATURANO, A. M. Estudo do efeito do peso de abate na qualidade da carne de cordeiros da raça Merino Australiano e Ile de France x Merino. 2003. Dissertação (Mestrado em Zootecnia) - Universidade Federal de Lavras, Lavras.

NERES, M. A.; MONTEIRO, A. L. G.; GARICA, C. A.; COSTA, C.; ARRIGONI, M. B.; ROSA, G. J. M. Forma física da ração e pesos de abate nas características de carcaça de cordeiros em creepfeeding. Revista Brasileira de Zootecnia, Viçosa, v. 30, n. 3, p. 948-954, 2001.

OSÓRIO, J. C. S.; OSÓRIO, M. T. M. Produção de carne: técnicas de avaliação in vivo e na carcaça. 2. ed. Pelotas: Ed. Universitária PREC/UfPel, 2005. 82 p.

PARDI, M. C.; SANTOS, I. F.; SOUZA, E. R.; PARDI, H. S. Ciência, higiene e tecnologia da carne: tecnologia da sua obtenção e transformação. Goiânia: Centro Editorial e Gráfico Universidade de Goiás, v. 1, 1993. 586 p. 
PÉREZ, J. R. O.; CARVALHO, P. A. Considerações sobre carcaças ovinas. In: PÉREZ, J. R. O. (Org.). Ovinocultura: aspectos produtivos. Lavras, MG: GAO, Universidade Federal de Lavras, 2002. p. 122-144.

PÉREZ, J. R. O.; BRESSAN, M. C.; BRAGAGNOLO, N.; PRADO, O. V.; LEMOS, A. L. S. C.; BONAGURIO, S. Efeito do peso ao abate de cordeiros Santa Inês e Bergamácia sobre o perfil de ácidos graxos, colesterol e propriedades químicas. Ciência e Tecnologia de Alimentos, Campinas, v. 22, n. 1, p. 11-18, 2002.

PINHEIRO, R. S. B.; SILVA SOBRINHO, A. G.; MARQUES, C. A. T.; YAMAMOTO, S. M. Biometría in vivo e da carcaça de cordeiros confinados. Archivos de Zootecnia, Córdoba, Espanha,v. 56, n. 216, p. 955-958, 2007.

PRACHE, S.; PRIOLO, A.; GROLIER, P. Persistence of carotenoid pigments in the blood of concentrate-finished grazing sheep: its significance for the traceability of grass-feeding. Journal of Animal Science, Champaign, v. 81, n. 2, p. 360-367, 2003.

PRIOLO, A.; MICOL, D.; AGABRIEL, J.; PRACHE, S.; DRANSFIELD, E. Effect of grass or concentrate feeding systems on lamb carcass and meat quality. Meat Science, Barking, v. 62, n. 2, p. 179-185, 2002.

SAÑUDO, C. Factors affecting carcass and meat quality in lambs. In: REUNIÃO ANUAL DA SOCIEDADE BRASILEIRA DE ZOOTECNIA, 39., 2002, Recife. Anais... Recife: Sociedade Brasileira de Zootecnia, 2002. p. $434-455$.
SAÑUDO, C.; SIERRA, I. Calidad de la canal en la espécie ovina. Revista Ovis, Zaragoza, v. 1, n. 1, p. 127 $153,1986$.

SILVA SOBRINHO, A. G.; PURCHAS, R. W.; KADIM, I. T.; YAMAMOTO, S. M. Características de qualidade da carne de ovinos de diferentes genótipos e idades ao abate. Revista Brasileira de Zootecnia, Viçosa, v. 34, n. 3, p. 1070-1078, 2005.

SILVA SOBRINHO, A. G. Body composition and characteristics of carcass from lambs of different genotypes and ages at slaughter. 1999. Dissertation (Post Doctorate in Sheep Meat Production) - Massey University, Palmerston North.

SILVA, S. R.; CADAVEZ V. P.; AZEVEDO, J. M. T. Carcaça e carne de borrego e cabrito. Avaliação da qualidade e da composição. Portugal: Serviços Gráficos/ UTAD, 2007.

WHIPPLE, G.; KOOHMARAIE, M.; DIKEMAN, M. E.; CROUSE, J. D.; HUNT, M. C.; KLEMM, R. D. Evaluation of attributes that affect Longissimus muscle tenderness in Boss taurus and Boss indicus cattle. Journalof Animal Science, Champaing, v. 68, n. 9, p. 2716-2728, 1990.

ZEOLA, N. M. B. L.; SILVA SOBRINHO, A. G.; GONZAGA NETO, S.; SILVA, A. M. A. Influência de diferentes níveis de concentrado sobre a qualidade da carne de cordeiros Morada Nova. Revista Portuguesa de Ciências Veterinárias, Lisboa, v. 97, n. 544, p. 175-180, 2002. 
